\title{
anu \\ Genome Analysis of an Alphabaculovirus Isolated from the Larch Looper, Erannis ankeraria
}

\author{
Long Liu ${ }^{1}\left(\mathbb{D}\right.$, Zhilin Zhang ${ }^{2}$, Chenglin Liu ${ }^{3}$, Liangjian $Q u^{3, *}$ and Dun Wang ${ }^{1, *(\mathbb{D}}$ \\ 1 State Key Laboratory of Crop Stress Biology for Arid Areas, College of Plant Protection, \\ Northwest A\&F University, Yangling, Xianyang 712100, China; dragonliulong@foxmail.com \\ 2 Forest Protection Station, Ulanqab 012000, China; zhangzhilin1761@163.com \\ 3 Institute of Forest Ecology, Environment and Nature Conservation, Chinese Academy of Forestry, \\ Beijing 100091, China; lc1@caf.ac.cn \\ * $\quad$ Correspondence: qulj2001@caf.ac.cn (L.Q.); wanghande@yahoo.com (D.W.); Tel.: +86-29-8709-1511 (D.W.)
}

check for updates

Citation: Liu, L.; Zhang, Z.; Liu, C.; Qu, L.; Wang, D. Genome Analysis of an Alphabaculovirus Isolated from the Larch Looper, Erannis ankeraria. Viruses 2022, 14, 34. https://doi.org/ $10.3390 / v 14010034$

Academic Editor:

Miguel López-Ferber

Received: 18 October 2021

Accepted: 21 December 2021

Published: 24 December 2021

Publisher's Note: MDPI stays neutral with regard to jurisdictional claims in published maps and institutional affiliations.

Copyright: () 2021 by the authors. Licensee MDPI, Basel, Switzerland. This article is an open access article distributed under the terms and conditions of the Creative Commons Attribution (CC BY) license (https:// creativecommons.org/licenses/by/ $4.0 /)$.

\begin{abstract}
The larch looper, Erannis ankeraria Staudinger (Lepidoptera: Geometridae), is one of the major insect pests of larch forests, widely distributed from southeastern Europe to East Asia. A naturally occurring baculovirus, Erannis ankeraria nucleopolyhedrovirus (EranNPV), was isolated from E. ankeraria larvae. This virus was characterized by electron microscopy and by sequencing the whole viral genome. The occlusion bodies (OBs) of EranNPV exhibited irregular polyhedral shapes containing multiple enveloped rod-shaped virions with a single nucleocapsid per virion. The EranNPV genome was $125,247 \mathrm{bp}$ in length with a nucleotide distribution of $34.9 \% \mathrm{G}+\mathrm{C}$. A total of 131 hypothetical open reading frames (ORFs) were identified, including the 38 baculovirus core genes and five multi-copy genes. Five homologous regions ( $h r s$ ) were found in the EranNPV genome. Phylogeny and pairwise kimura 2-parameter analysis indicated that EranNPV was a novel group II alphabaculovirus and was most closely related to Apocheima cinerarium NPV (ApciNPV). Field trials showed that EranNPV was effective in controlling E. ankeraria in larch forests. The above results will be relevant to the functional research on EranNPV and promote the use of this virus as a biocontrol agent.
\end{abstract}

Keywords: baculovirus; Alphabaculovirus; Erannis ankeraria; EranNPV; complete genome

\section{Introduction}

Baculoviruses are pathogenic viruses that mainly infect insects of orders Lepidoptera, Diptera, and Hymenoptera. Baculoviruses typically infect only one or a few related insect species and are thus successfully employed as environmentally safe biopesticides for pest control [1-3]. Baculoviruses are also well known in biotechnology, as baculoviruses offer efficient expression systems for various applications ranging from routine expression of exogenous genes in the laboratory to vaccine production and gene therapy $[4,5]$.

Members of the Baculoviridae are characterized by possessing large, circular, supercoiled, and double-stranded DNA genomes that combine with capsid proteins to form an enveloped nucleocapsid. The baculoviral genomes range from approximately 80 to $180 \mathrm{kbp}$ and encode between 90 and 180 genes [6]. The production of two types of structurally and functionally distinct progeny viruses is a striking feature of the typical baculovirus life cycle. One virion phenotype is called the budded virus (BV), which is responsible for spreading infection systemically from cell to cell throughout the host, and another one is referred to as the occlusion-derived virus (ODV) transmitting infection orally from insect to insect [7]. ODVs are embedded in proteinaceous occlusion bodies (OBs), which provide the virus with physical protection in the environment. Based on the OB morphology, baculoviruses comprise nucleopolyhedroviruses (NPVs) or granuloviruses (GVs) [8]. The family Baculoviridae is composed of four genera: Alphabaculovirus (NPVs that specifically infect the insect order Lepidoptera), Betabaculovirus (GVs that specifically infect the insect 
order Lepidoptera), Gammabaculovirus (NPVs that specifically infect the insect order Hymenoptera), and Deltabaculovirus (NPVs that specifically infect the insect order Diptera) [9]. Alphabaculovirus can be further subdivided into two lineages, group I and group II. Group I alphabaculoviruses use GP64 as their envelope fusion protein (EFP) in the BV phenotype, whereas group II alphabaculoviruses as well as betabaculoviruses and deltabaculoviruses lack GP64 and exploit F protein as the EFP [10]. Studies on the whole genome of baculoviruses are helpful in guiding our current understanding of baculovirus, including the biotechnological use of the viruses and the revelation of intrinsic attributes critical for virus identification and classification, gene function, and insecticidal potential [11,12].

The larch looper, Erannis ankeraria (Lepidoptera: Geometridae), was one of the major insect pests of larch forests, widely distributed from southeastern Europe to East Asia. The larvae of this moth can lead to serious damages to trees from Larix spp., Quercus L., and Picea mills [13]. In the current study, Erannis ankeraria nucleopolyhedrovirus (EranNPV) was isolated from infected E. ankeraria larvae. EranNPV was examined by electron microscopy, and the complete genome was determined, analyzed, and compared to other fully sequenced baculovirus genomes. The size of the EranNPV genome was found to be $125,247 \mathrm{bp}$. Phylogenetic analysis showed that EranNPV was a group II alphabaculovirus and was most closely related to Apocheima cinerarium nucleopolyhedrovirus (ApciNPV). Additionally, EranNPV was effective in controlling E. ankeraria in larch forests, indicating a potential of this virus to be developed as bio-pesticide.

\section{Materials and Methods}

\subsection{Virus Isolation}

EranNPV was isolated from a larval cadaver of E. ankeraria collected in Ulanqab, Inner Mongolia, China, in June 2018. The virus was propagated in the third instar laboratoryreared E. ankeraria larvae. EranNPV OBs were purified from larval cadavers dying from infection by steps of maceration, homogenization, filtration, centrifugation, and sucrose density-gradient ultracentrifugation, as described previously [14].

\subsection{Electron Microscopy}

For the scanning electron microscope (SEM), purified OBs were observed using a scanning electron microscope (Hitachi S-3400N, Hitachi, Tokyo, Japan) at a $5 \mathrm{kV}$ acceleration voltage. For the transmission electron microscope (TEM), EranNPV OBs were embedded in $2 \%$ agarose and fixed in $2.5 \%$ glutaraldehyde at $4{ }^{\circ} \mathrm{C}$ overnight. After six rinses with $0.2 \mathrm{~mol} / \mathrm{L}$ phosphate buffer ( $\mathrm{pH}$ 7.4), the samples were post-fixed in $1 \%$ osmium tetroxide at room temperature for $2 \mathrm{~h}$. Fixed samples were rinsed, dehydrated, embedded, sectioned, and stained as described previously [15]. Ultrathin sections were imaged under a Hitachi HT7700 (Hitachi, Tokyo, Japan) transmission electron microscope at an accelerating voltage of $80 \mathrm{kV}$.

\subsection{Viral DNA Isolation, Sequencing, and Assembly}

Viral genomic DNA was isolated from purified OBs according to the following method. The purified OBs were resuspended in $100 \mathrm{mM} \mathrm{Na}_{2} \mathrm{CO}_{3}$ and incubated at $37^{\circ} \mathrm{C}$ for $30 \mathrm{~min}$. The $\mathrm{pH}$ value of the solution was adjusted to eight with $1 \mathrm{M} \mathrm{HCl}$. RNase A (final concentration was $45 \mu \mathrm{g} / \mathrm{mL}$ ) was added to the solution and incubated at $37^{\circ} \mathrm{C}$ for $10 \mathrm{~min}$. Virion particles were disintegrated by adding SDS (final concentration was $1 \%$ ) and proteinase $\mathrm{K}$ (final concentration was $250 \mu \mathrm{g} / \mathrm{mL}$ ), followed by incubation for $1 \mathrm{~h}$ at $37^{\circ} \mathrm{C}$. After extracting with phenol/chloroform/isoamyl alcohol (25:24:1), the viral DNA was precipitated by ethanol. The DNA concentration was determined by spectrophotometry, and the DNA purity was verified by measuring the $260 / 280$ ratio.

EranNPV full genome sequencing was performed on both the Illumina NovaSeq 6000 system and the PromethION platform from Oxford Nanopore Technologies. For Illumina NovaSeq 6000 system, 18,064,430 clean reads were generated. The GC, Q20, and Q30 contents were $34.64 \%, 97.18 \%$, and $91.97 \%$, respectively. For the PromethION platform, a 
total of 33,114 reads were obtained with an N50 size of 30,295 bp, of which the average length was 30,199 bp. The Unicycler software (version 2.1.2) was used to assemble the sequence data. A high-quality genome skeleton (contig) was obtained by assembling highaccuracy Illumina reads $(\mathrm{Q} 30>85 \%)$, followed by the connection of the contig using the Nanopore reads.

\subsection{Genome Sequence Analysis}

The open reading frames (ORFs) potentially encoding proteins with at least 50 amino acids and minimal overlap were predicted using FGENESV (http:/ / linux1.softberry.com/ berry.phtml, accessed on 18 June 2021) and the NCBI ORF Finder (http:/ / www.ncbi.nlm. nih.gov / gorf/gorf.html, accessed on 18 June 2021). The identified ORFs were annotated according to homology by the NCBI Protein-Protein BLAST algorithm (https://blast. ncbi.nlm.nih.gov / Blast.cgi, accessed on 20 June 2021). The complete genomic data were submitted to GenBank under accession number OK091173.

Homologous regions ( $h r s$ ) were identified using the tandem repeats finder [16] and Blast2seq [17]. The alignment of individual repeats from the hrs was performed using ClustalW in MEGA software (version 10.1.8) [18]. The BoxShade server (https:/ / embnet. vital-it.ch/software/BOX_form.html, accessed on 26 June 2021) was employed to display the alignment and repeat the consensus sequence. The ViennaRNA server (http:/ / rna.tbi. univie.ac.at/, accessed on 27 June 2021) was applied to predict the secondary structure of the conserved $h r$ sequence [19].

Identities among proteins encoded by EranNPV and their homologous proteins in selected genomes were computed using BioEdit software (version 7.0.9.0) with default parameters. Gene parity plots were generated to compare ORF organization between EranNPV and the selected baculoviruses [20].

\subsection{Phylogeny and Kimura 2-Parameter Analysis}

Protein sequences encoded by the 38 core genes were extracted from 107 completely sequenced baculovirus genomes (Tables S1 and S2) and aligned using the MAFFT method with auto strategy and normal alignment mode [21]. The Gblocks were used to remove poorly aligned sites with default parameters [22]. Concatenation of alignments of 38 core protein sequences from 107 baculovirus species was implemented using PhyloSuite (version 1.2.2) [23]. The best partitioning scheme for maximum likelihood (ML) was determined by PartitionFinder2 according to the Bayesian information criterion (BIC) and a greedy search algorithm with branch lengths linked [24]. ML tree was inferred with IQ-TREE under Ultrafast bootstrap with 5000 replicates, as well as the SH-aLRT test with 1000 replicates [25-27]. For phylogenetic analysis of the inhibitor of apoptosis protein (IAP), the alignment of amino acid sequences and the construction of ML trees were carried out with the same methods. ModelFinder was applied to determine the best-fit model of amino acid evolution for IAP proteins with the default settings according to BIC [28]. The best-fit model for IAP was WAG+F+I+G4.

Kimura 2-parameter (K2P) pairwise distances from aligned nucleotide sequences of polyhedrin, lef-8, lef-9, and concatenated polyhedrin/lef-8/lef-9/fragments were calculated separately using the pairwise distance calculation in MEGA software (version 10.1.8). The variation among sites was set to be uniform. Gaps within the alignment were treated as pairwise deletions. K2P pairwise distances of concatenated nucleotide sequences of the 38 core genes were calculated as described previously [29].

\subsection{Field Testing of EranNPV}

As an attempt to explore the pesticidal potential of EranNPV, field trials against a natural infestation of E. ankeraria larvae were conducted in a planted Larix principis-rupprechtii forest in Ulanqab, Inner Mongolia, China, in May 2019. The concentration of EranNPV OBs was determined by a standard hemocytometer. EranNPV OBs were resuspended in tap water. The concentration of EranNPV OBs used to spray was $1.09 \times 10^{8} \mathrm{OBs} / \mathrm{mL}$. The 
application of the treatment was imposed on trees using a motorized sprayer (3WZ-300L, Nantong Guangyi Electromechanical Co., Ltd., Hai'an, Jiangsu Province, China) during evening hours, with the spray evenly distributed on the leaf surface until the spray droplet drops as the standard. The water spraying was set as a blank control. The plot sizes of the treatment and non-treated control were $100 \mathrm{~m}^{2}$. After spraying, twenty trees were selected from each plot, and one branch containing twenty larvae was selected from each tree and was covered with the insect rearing cage $(35 \mathrm{~cm}$ long and $10 \mathrm{~cm}$ in diameter). The surviving larvae in the cages were recorded at $12 \mathrm{~d}$ post applications.

\section{Results and Discussion}

\subsection{Ultrastructural Features of Occlusion Bodies}

SEM revealed EranNPV OBs to be irregular polyhedral shapes (Figure 1A). The irregular shape of OBs is the typical morphological characteristic of alphabaculoviruses described in other studies, such as Mythimna unipuncta nucleopolyhedrovirus isolate KY310 (MyunNPV-KY310) [30], Cryptophlebia peltastica nucleopolyhedrovirus (CrpeNPV) [31], and Operophtera brumata nucleopolyhedrovirus (OpbuNPV) [32], etc. TEM showed that each OB contained numerous enveloped rod-shaped virions with a single nucleocapsid within the ODV (Figure 1B).

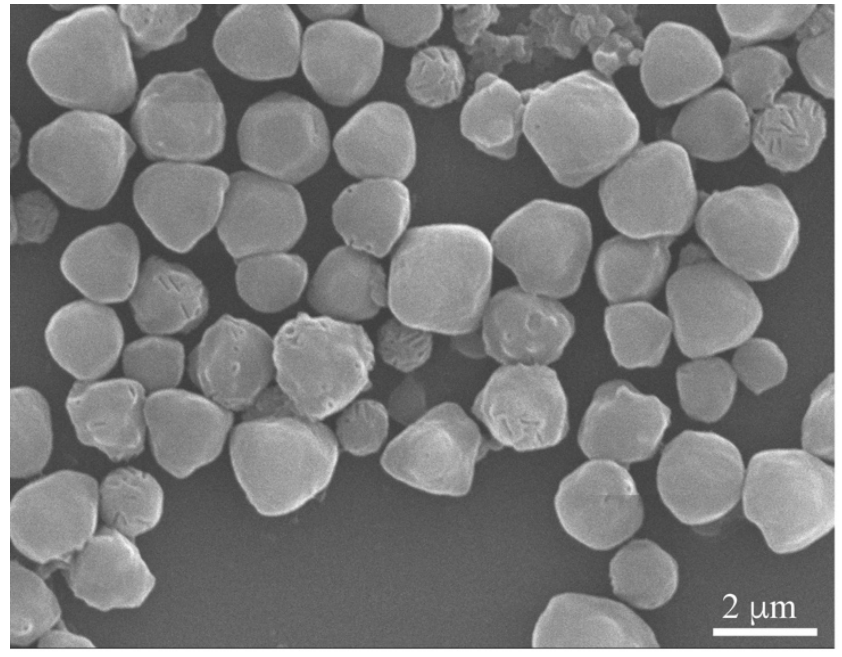

(A)

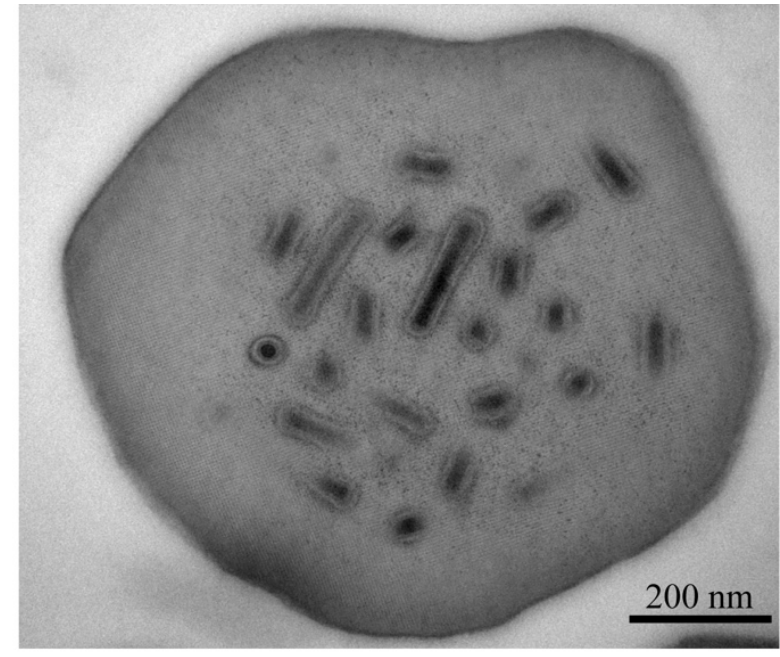

(B)

Figure 1. Occlusion bodies of EranNPV. (A) The scanning electron micrograph of occlusion bodies; (B) the transmission electron micrograph of ultrathin sections through occlusion bodies.

\subsection{Features of EranNPV Genome}

The complete genome of the EranNPV isolate consisted of 125,247 bp with $34.9 \%$ GC content. The genome size and the GC content falls into the range of other sequenced baculoviruses [6]. A total of 131 putative ORFs that encode at least 50 amino acids with minimal overlaps were identified and annotated in the EranNPV genome. The coding regions covered $91.46 \%$ of the whole genome. The locations and directions of identified ORFs were illustrated in the circular genome map, and the adenine of the polyhedrin gene initiation codon was defined as the first nucleotide position (Figure 2). The ORFs exhibited almost equal distribution on both strands of the DNA throughout the genome, with 68 ORFs in clockwise (+) direction and 63 ORFs in anticlockwise (-) direction. EranNPV genome contained the 38 core genes that were found in all baculovirus genomes $[33,34]$, 22 lepidopteran baculovirus conserved genes, 64 common genes that possessed homolog sequences in other baculoviruses, and 7 unique genes (orf6, orf40, orf48, orf51, orf89, orf106, and orf116) without homologs in Baculoviridae (Figure 2). 


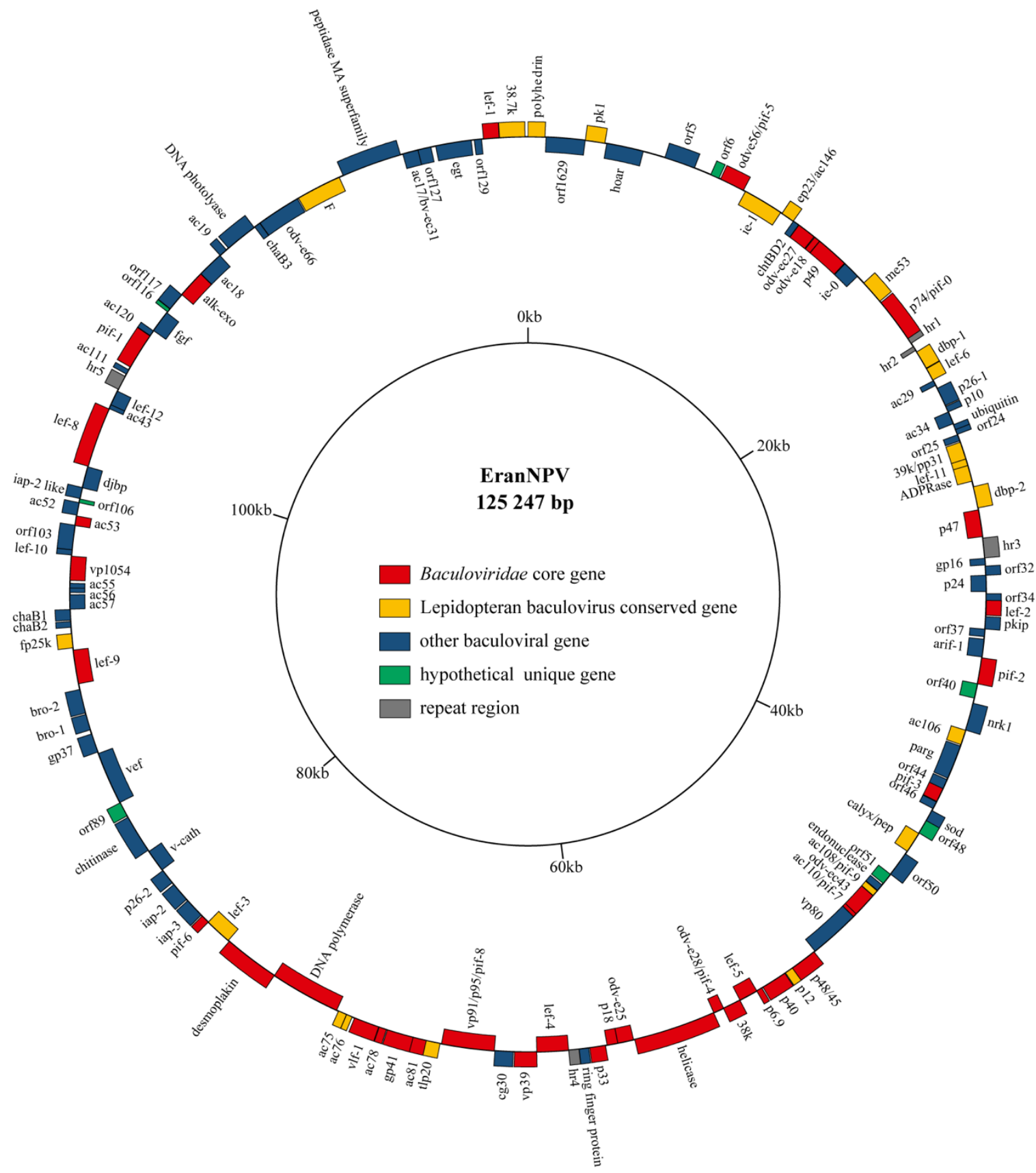

Figure 2. Circular map of EranNPV genome. Genes in the positive strand are drawn to the outside of the circle, and those in the negative strand are on the inside. The colors represent gene types: red represents baculovirus core genes, yellow represent genes present in all lepidopteran baculoviruses, blue represents other baculoviral genes, green represents hypothetical genes unique to EranNPV. Gray squares represent repeat regions.

Among 131 ORFs predicted in the EranNPV genome, regions 200 bp upstream of the initiation codon were screened. Early promoters consisting of a TATA box motif followed by a 20-40 bp downstream CAKT were found in 36 ORFs. One hundred and five ORFs harbored a baculovirus late promoter element (DTAAG). Twenty-eight ORFs had both an early and late promoter motif. A total of 18 ORFs lacked any recognizable canonical promoter motif (Table S3). 


\subsection{Homologous Regions}

Most baculovirus genomes contain repeated AT-rich sequences called homologous regions (hrs). Hrs are interspersed at different locations within the genome and characterized by comprising a number of tandem repeats that include an imperfect palindromic core [35]. The hrs of different baculoviruses differ widely in the sequence length, composition, and number of repeats [36]. The hrs play putative or demonstrated roles as origins of DNA replication and enhancers of gene transcription [37-39]. Five hrs were identified in the EranNPV genome with an AT content of 72-74\%. Except for $h r 2$ that was positioned in the anticlockwise direction, all the $h r s$ were positioned in the clockwise direction in the genome. As shown in Figure 3A, the hrs of the EranNPV genome were composed of 4-15 tandem repeats of about $58 \mathrm{bp}$ in length. The $h r 1$ and $h r 2$ were located between $p 74$ and $d b p-1$ and contained five and four repeat units, respectively. The $h r 3$ was the longest and was located at the intergenic region between $p 47$ and gp16 with a total of 15 copies of tandem repeats. The hr4 was located between ring finger protein and lef-4 and was made of eight repeat units. The $h r 5$ was present in the intergenic region between lef-12 and ac111 with 11 tandem repeats. The alignment and secondary structure prediction of the tandem repeats (Figure 3B,C) indicated that the repeat units of EranNPV hrs were imperfect inverted repeat sequences.
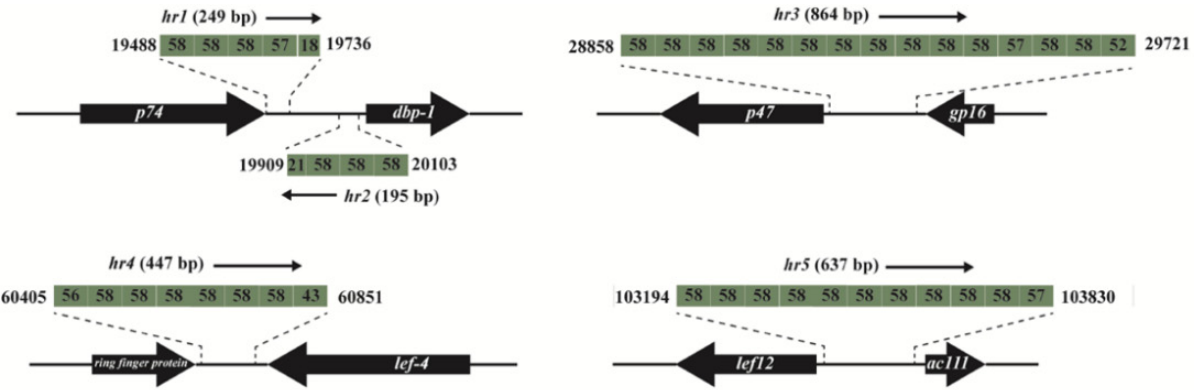

(A)

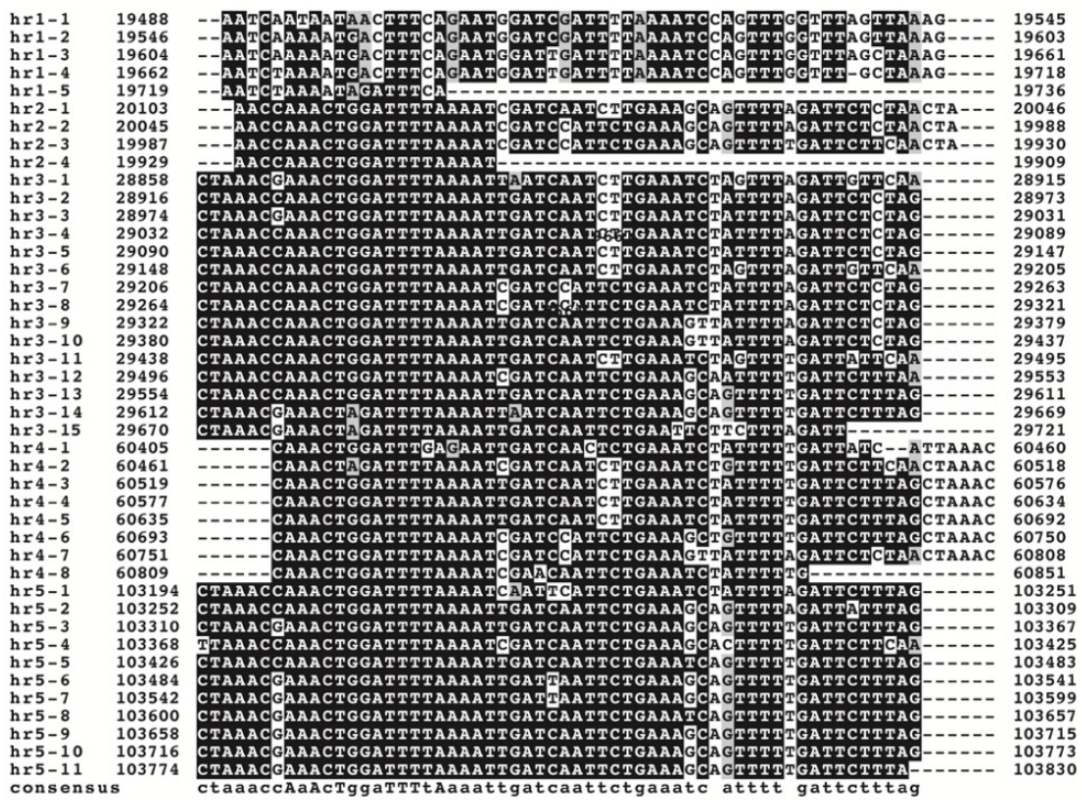

(B)

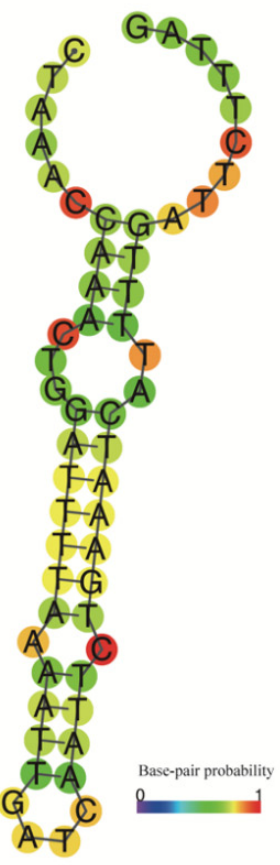

(C)

Figure 3. Analysis of EranNPV homologous regions (hrs). (A) The schematic diagram for location and structure of the five $h r s$ in the EranNPV genome. Green blocks indicate $h r s$ repeat units with the length of each unit. (B) Sequence alignment of EranNPV $h r$ repeat units. The completely identical residues in the alignment were indicated by uppercase letters in the consensus sequence, and a majority of identical residues in the alignment were denoted using lowercase letters. (C) Secondary structure prediction of the conserved $h r$ sequence. 


\subsection{Phylogenetic Analysis of EranNPV}

EranNPV encoded the F protein and lacked the gp64 gene, indicating that it was a group II alphabaculovirus. Phylogeny among EranNPV and other completely sequenced baculoviruses based on concatenated alignments of the 38 baculovirus core protein sequences confirmed that the EranNPV belonged to group II of genus Alphabaculovirus and shared the closest phylogenetic relationship with ApciNPV (Figure 4). From the ML phylogram, alphabaculoviruses clustered into a monophyletic group, and group I alphabaculoviruses formed a monophyletic clade within the alphabaculovirus group. However, three minor monophyletic subgroups containing nine species were placed in a basal position relative to other alphabaculoviruses. This topological structure is in accordance with previous studies [10].

Tree scale: 1

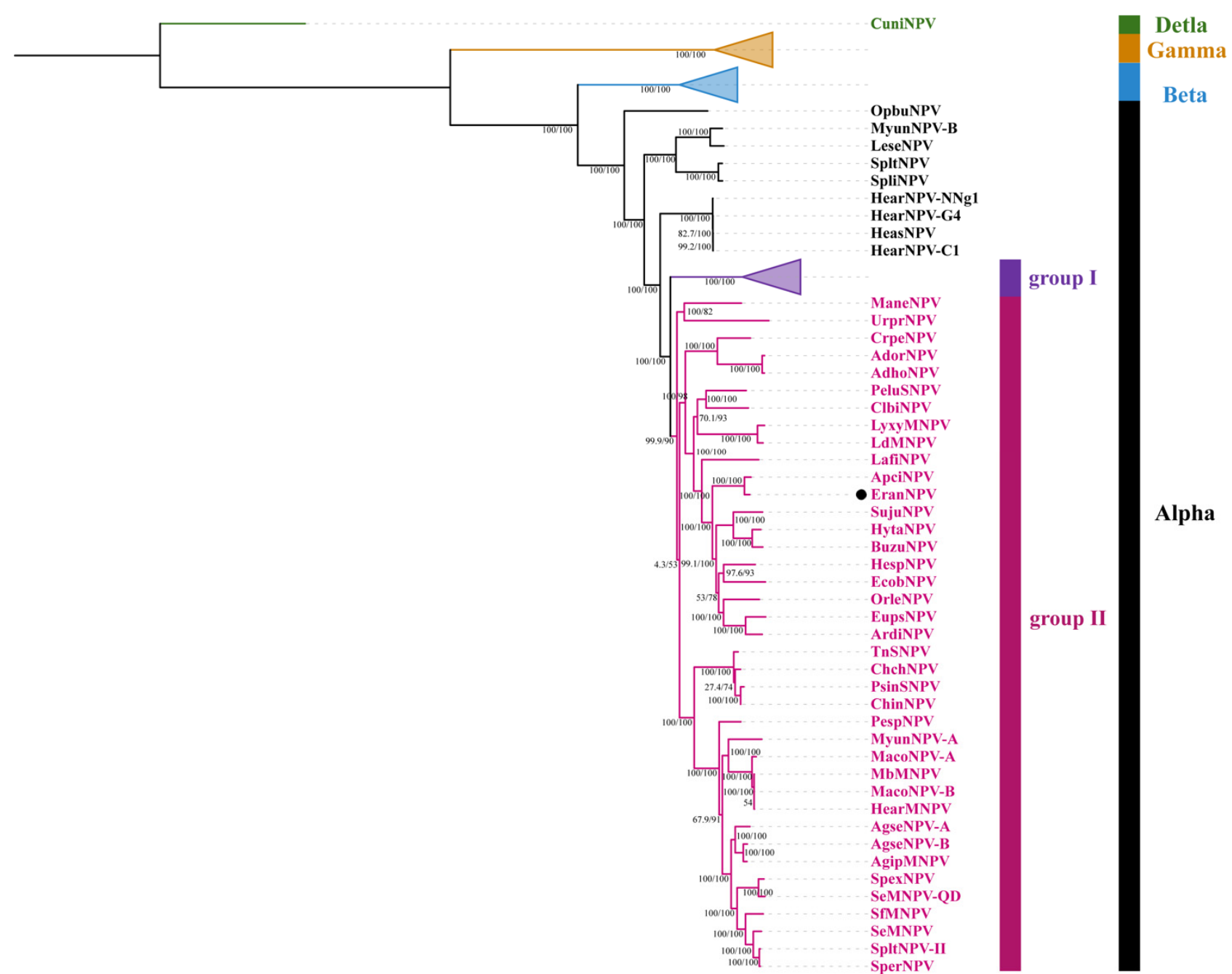

Figure 4. ML tree inferred from the concatenated alignments of 38 core protein sequences from 107 baculoviruses using IQ-TREE. Bootstrap support values and SH-aLRT values are indicated on branches. EranNPV is marked by the black dot.

Based on pairwise nucleotide distances using the K2P substitution model, two baculoviruses should be deemed as different virus species if their K2P pairwise distances of the polyhedrin, lef-8, and lef-9 genes are larger than 0.05 substitutions/site [40]. The K2P pairwise distances of polyhedrin, lef-8, lef-9, and concatenated polyhedrin/lef-8/lef-9 fragments between EranNPV and other related NPVs were more than 0.05 substitutions/site (Table 1). 
Additionally, pairwise K2P nucleotide distances of concatenated 38 core genes between EranNPV and other related NPVs were all larger than the threshold of 0.072 (Table 1), which was proposed by Wennmann et al. (2018) to separate two baculoviruses species. The above results indicated that EranNPV was a distinct alphabaculovirus.

Table 1. Pairwise distances of the nucleotide sequences of (A) polyhedrin (polh) and concatenated polh/lef-8/lef-9 fragments, (B) lef- 9 and lef- 8 , and (C) concatenated nucleotide sequences of the 38 core genes among EranNPV and other related species.

\begin{tabular}{|c|c|c|c|c|c|c|c|c|c|c|c|}
\hline \multicolumn{12}{|c|}{ (A) } \\
\hline polh & polh/lef-8/lef-9 & 1 & 2 & 3 & 4 & 5 & 6 & 7 & 8 & 9 & 10 \\
\hline 1 & EranNPV & - & 0.12 & 0.35 & 0.34 & 0.34 & 0.34 & 0.33 & 0.33 & 0.33 & 0.34 \\
\hline 2 & ApciNPV & 0.09 & - & 0.36 & 0.35 & 0.34 & 0.35 & 0.34 & 0.33 & 0.35 & 0.34 \\
\hline 3 & SujuNPV & 0.20 & 0.20 & - & 0.30 & 0.31 & 0.36 & 0.34 & 0.34 & 0.36 & 0.35 \\
\hline 4 & HytaNPV & 0.22 & 0.21 & 0.23 & - & 0.18 & 0.34 & 0.33 & 0.32 & 0.33 & 0.32 \\
\hline 5 & BuzuNPV & 0.21 & 0.20 & 0.24 & 0.17 & - & 0.35 & 0.34 & 0.33 & 0.33 & 0.34 \\
\hline 6 & HespNPV & 0.22 & 0.23 & 0.23 & 0.22 & 0.23 & - & 0.34 & 0.34 & 0.35 & 0.35 \\
\hline 7 & EcobNPV & 0.21 & 0.22 & 0.23 & 0.19 & 0.23 & 0.22 & - & 0.34 & 0.33 & 0.34 \\
\hline 8 & OrleNPV & 0.21 & 0.20 & 0.22 & 0.19 & 0.21 & 0.21 & 0.21 & - & 0.31 & 0.30 \\
\hline 9 & EupsNPV & 0.27 & 0.28 & 0.26 & 0.24 & 0.22 & 0.25 & 0.24 & 0.22 & - & 0.24 \\
\hline 10 & ArdiNPV & 0.23 & 0.22 & 0.25 & 0.19 & 0.20 & 0.21 & 0.21 & 0.21 & 0.21 & - \\
\hline \multicolumn{12}{|c|}{ (B) } \\
\hline lef- 8 & lef-9 & 1 & 2 & 3 & 4 & 5 & 6 & 7 & 8 & 9 & 10 \\
\hline 1 & EranNPV & - & 0.12 & 0.35 & 0.34 & 0.35 & 0.33 & 0.33 & 0.34 & 0.33 & 0.37 \\
\hline 2 & ApciNPV & 0.12 & - & 0.36 & 0.36 & 0.36 & 0.36 & 0.35 & 0.35 & 0.36 & 0.36 \\
\hline 3 & SujuNPV & 0.39 & 0.40 & - & 0.31 & 0.32 & 0.37 & 0.32 & 0.34 & 0.38 & 0.35 \\
\hline 4 & HytaNPV & 0.38 & 0.38 & 0.31 & - & 0.16 & 0.34 & 0.32 & 0.31 & 0.35 & 0.35 \\
\hline 5 & BuzuNPV & 0.38 & 0.37 & 0.33 & 0.18 & - & 0.34 & 0.30 & 0.30 & 0.35 & 0.35 \\
\hline 6 & HespNPV & 0.38 & 0.39 & 0.40 & 0.38 & 0.40 & - & 0.35 & 0.35 & 0.35 & 0.35 \\
\hline 7 & EcobNPV & 0.37 & 0.37 & 0.39 & 0.38 & 0.40 & 0.37 & - & 0.33 & 0.33 & 0.36 \\
\hline 8 & OrleNPV & 0.37 & 0.36 & 0.38 & 0.36 & 0.38 & 0.38 & 0.37 & - & 0.31 & 0.29 \\
\hline 9 & EupsNPV & 0.35 & 0.36 & 0.38 & 0.34 & 0.36 & 0.37 & 0.37 & 0.34 & - & 0.27 \\
\hline 10 & ArdiNPV & 0.36 & 0.36 & 0.38 & 0.35 & 0.37 & 0.39 & 0.37 & 0.33 & 0.24 & - \\
\hline \multicolumn{12}{|c|}{ (C) } \\
\hline \multicolumn{2}{|c|}{38 Core Genes } & 1 & 2 & 3 & 4 & 5 & 6 & 7 & 8 & \multicolumn{2}{|c|}{9} \\
\hline 1 & EranNPV & & & & & & & & & & \\
\hline 2 & ApciNPV & 0.13 & & & & & & & & & \\
\hline 3 & SujuNPV & 0.49 & 0.48 & & & & & & & & \\
\hline 4 & HytaNPV & 0.51 & 0.49 & 0.45 & & & & & & & \\
\hline 5 & BuzuNPV & 0.48 & 0.47 & 0.43 & 0.25 & & & & & & \\
\hline 6 & HespNPV & 0.49 & 0.47 & 0.51 & 0.51 & 0.50 & & & & & \\
\hline 7 & EcobNPV & 0.49 & 0.47 & 0.50 & 0.51 & 0.50 & 0.50 & & & & \\
\hline 8 & OrleNPV & 0.49 & 0.47 & 0.50 & 0.49 & 0.48 & 0.48 & 0.50 & & & \\
\hline 9 & EupsNPV & 0.49 & 0.48 & 0.51 & 0.50 & 0.50 & 0.49 & 0.50 & 0.46 & & \\
\hline 10 & ArdiNPV & 0.49 & 0.48 & 0.50 & 0.49 & 0.49 & 0.49 & 0.49 & 0.46 & & \\
\hline
\end{tabular}

\subsection{Genome Comparison}

The gene content and order of the EranNPV genome were compared with six representative baculoviruses: Autographa californica multiple nucleopolyhedrovirus (AcMNPV, group I alphabaculovirus), Helicoverpa armigera nucleopolyhedrovirus G4 (HearNPV-G4, minor group alphabaculovirus), ApciNPV (group II alphabaculovirus), Cydia pomonella granulovirus (CpGV, betabaculovirus), Neodiprion lecontei nucleopolyhedrovirus (NeleNPV, gammabaculovirus) and Culex nigripalpus nucleopolyhedrovirus (CuniNPV, deltabaculovirus). EranNPV shared 103 homologous ORFs with AcMNPV, 105 with 
HearNPV-G4, 114 with ApciNPV, 78 with CpGV, 47 with NeleNPV, and 39 with CuniNPV. Regarding the 38 core proteins, EranNPV shared an average amino acid identity of $43.1 \%, 49.9 \%, 82.5 \%, 29.4 \%, 20.7 \%$, and $15.5 \%$ with the above six viruses, respectively. Gene parity plots analysis (Figure 5) revealed that the gene order of EranNPV was highly collinear with ApciNPV and partially collinear with AcMNPV, HearNPV-G4, and CpGV. However, the gene arrangement of EranNPV was noticeably divergent with NeleNPV and CuniNPV.
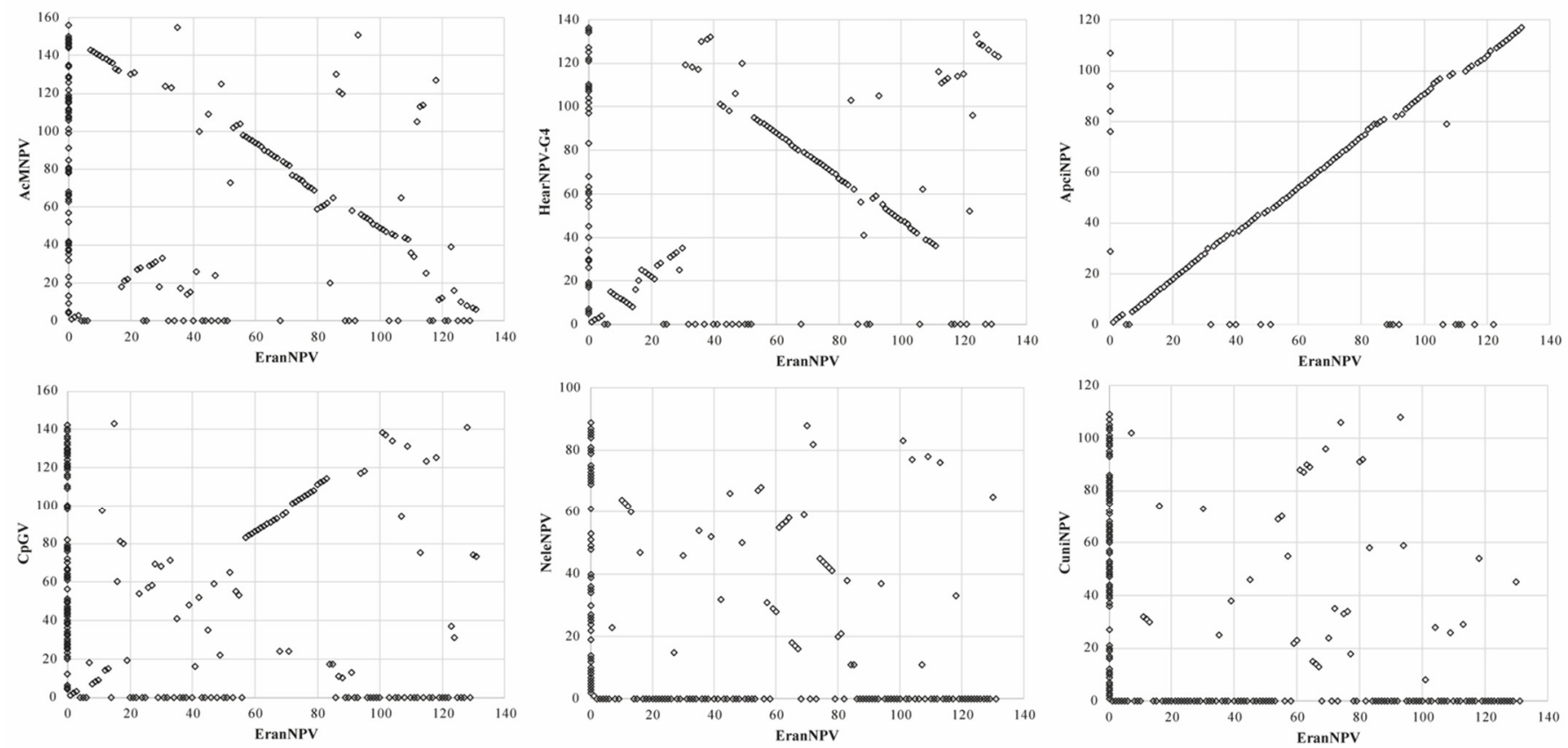

Figure 5. Gene parity plots analysis. Gene parity plots of EranNPV compared to AcMNPV, HearNPVG4, ApciNPV, CpGV, NeleNPV, and CuniNPV based on ORF order. Black squares indicate the presence and relative position of ORFs in the EranNPV genome with those from other viruses.

\subsection{Gene Content of EranNPV}

\subsubsection{Classification of EranNPV Genes}

As in other baculoviruses, annotated ORFs of the EranNPV genome can be categorized based on their function, including genes related to replication, transcription, structure and oral infectivity, auxiliary genes, and genes with unknown function (Table 2). Fifteen genes involved in viral DNA replication were found in the EranNPV genome. Other DNA replication genes, including helicase-2, DNA ligase, pcna, lef-7, rr1, rr2, and dUTPase, were absent from the EranNPV genome. Except for EranNPV, some other alphabaculoviruses also lack these seven genes related to DNA replication, such as ApciNPV, Buzura suppressaria nucleopolyhedrovirus (BuzuNPV), and Adoxophyes orana nucleopolyhedrovirus (AdorNPV). Two group I alphabaculoviruses, Choristoneura occidentalis nucleopolyhedrovirus (Choc$\mathrm{NPV}$ ) and Choristoneura rosaceana nucleopolyhedrovirus (ChroNPV), contain pcna but lack the remaining six genes [41]. Helicase-2 and DNA ligase are considered to be implicated in DNA repair and recombination [42]. Homologs of pcna are only present in a few alphabaculoviruses from group I. Homologs of lef-7 were found to be present in several alphabaculoviruses and in a few betabaculoviruses specific for noctuid hosts [43]. AcMNPV lef-7 is a replication factor associated with the manipulation of the DNA damage response (DDR) of the host to promote efficient virus replication [44]. Homologs of Rr1, rr2, and dUTPase coding for enzymes related to nucleotide metabolism were found in some alphabaculoviruses and betabaculoviruses [45].

EranNPV encoded all baculovirus transcription genes except for ie-2 and pe38. Additionally, 32 structural genes were present in the EranNPV genome; however, EranNPV lacked homologs to $g p 50$ and gp64. 
Successful oral infection of baculoviruses relies on a multiprotein complex of per os infectivity factors (PIFs) on the ODV envelope [46]. The EranNPV contained all 10 baculovirus pif genes, pif-0-pif-9. Except for pif-9, all the pif genes encoded by EranNPV were baculoviral core genes. Besides PIFs, the EranNPV also possessed a major ODV-specific envelope protein, ODV-E66, that is conserved in all lepidopteran baculoviruses $[47,48]$. The ODV-E66 plays an important role in the penetration of the peritrophic membrane (PM) during oral infection [49].

Auxiliary genes are a class of genes that are not essential for viral DNA replication, gene expression, and formation of progeny virion, but they provide the virus some selective advantages in the context of species-specific virus-host interactions [50]. A total of 20 auxiliary genes were found in the EranNPV genome. Additional genes ( $p t p-1, p t p-2, c t l-1$, ctl-2) also known as auxiliary genes were not found in EranNPV genome.

Table 2. Classification of EranNPV genes.

\begin{tabular}{|c|c|c|}
\hline Gene Function & Genes Present in EranNPV (ORF No.) & Genes Missing in EranNPV \\
\hline Replication & $\begin{array}{c}\text { ie-1 (8), me53 (15), dbp-1 (17), lef-11 (27), dbp-2 (29), lef-2 (35), nrk-1 (41), parg } \\
\text { (43), endonuclease (52), helicase (64), DNA polymerase (80), lef-3 (82), alk-exo } \\
\text { (118), DNA photolyase (121), lef-1 (130) }\end{array}$ & $\begin{array}{l}\text { helicase-2, DNA ligase, dUTPase, } \\
\text { pcna, lef7, rr1, rr2 }\end{array}$ \\
\hline Transcription & $\begin{array}{c}\text { ie-0 (14), lef-6 (18), } 39 \mathrm{k} / p p 31 \text { (26), p47 (30), lef-5 (61), lef-4 (69), vlf-1 (77), lef-9 } \\
\text { (94), lef-10 (102), lef-8 (109), lef-12 (111) }\end{array}$ & $i e-2, p e 38$ \\
\hline Structure & $\begin{array}{l}\text { polyhedrin (1), orf1629 (2), pk-1 (3), odv-ec27 (11), odv-e18 (12), p49 (13), p10 (21), } \\
\text { gp16 (31), p24 (33), pkip (36), calyx/pep (49), odv-ec43 (54), vp80 (56), p48/45 (57), } \\
\text { p12 (58), p40 (59), p6.9 (60), 38k (62), odv-e25 (65), p18 (66), p33 (67), vp39 (70), } \\
\text { cg30 (71), tlp-20 (73), ac81 (74), gp41 (75), ac78 (76), desmoplakin (81), fp25k (95), } \\
\text { vp1054 (101), ac53 (104), F (124), ac17/bv-ec31 (126) }\end{array}$ & gp50, gp64 \\
\hline Oral infectivity & $\begin{array}{l}\text { odv-e56/pif-5 (7), p74/pif-0 (16), pif-2 (39), pif-3 (45), ac108/pif-9 (53), ac110/pif-7 } \\
\text { (55), odv-e28/pif-4 (63), vp91/p95/pif-8 (72), pif-6 (83), pif-1 (113), odv-e66 (123) }\end{array}$ & \\
\hline Auxiliary & $\begin{array}{c}\text { p26-1 (20), ubiquitin (23), ADPRase (28), arif-1 (38), sod (47), ring finger protein } \\
(68), \text { iap-3 (84), iap-2 (85), p26-2 (86), v-cath (87), chitinase (88), vef (90), gp37 } \\
(91), \text { bro-1 (92), bro-2 (93), iap-2-like (107), djbp (108), fgf (115), egt (128), } \\
38.7 k(131)\end{array}$ & $p t p-1, p t p-2, c t l-1, c t l-2$ \\
\hline Unknown & 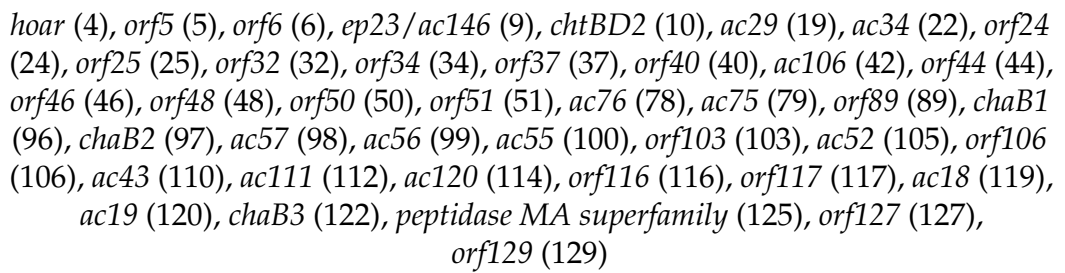 & ac145 \\
\hline
\end{tabular}

\subsubsection{Analysis of EranNPV Multi-Copy Genes}

To date, most sequenced baculovirus genomes contain one to 16 copies of baculovirus repeated ORFs (bro) whose function is not well characterized [51]. Studies on the Bombyx mori nucleopolyhedrovirus (BmNPV) bro genes revealed that BRO proteins could bind to DNA and were related to influencing host DNA replication [52]. Two adjacent bro genes, bro-1 (ORF92) and bro-2 (ORF93), were identified in the EranNPV genome.

Homologs of DNA binding protein $(d b p)$ were found in all sequenced baculovirus genomes except for CuniNPV, and multiple copies of the $d b p$ gene are present in group II alphabaculoviruses. The $d b p$ gene is involved in unwinding and annealing DNA during replication [53]. Two copies of the $d b p$ gene were found in the EranNPV genome.

To abrogate programmed cell death, baculoviruses code for two families of genes blocking apoptosis that is triggered at the early stages of infection, p35, and inhibitor of apoptosis (iap). Iaps are found to make up for the lack of $p 35$ [54,55]. Within the baculoviruses, six lineages of iap genes have been identified, named iap-1 to iap-6. IAP-1, $-2,-3$, and -5 proteins each contain two well-conserved baculoviral IAP repeat (BIR) domains and a 
really interesting new gene (RING) domain at the C-terminal. IAP-4 proteins are composed of a ring domain and a single BIR domain that is smaller than the normal BIR domain. Betabaculoviruses IAPs containing a single BIR and RING belong to the IAP-6 lineage. A small number of alphabaculovirus IAP-2 homologs that lack a copy of BIR are referred to as IAP-2-like proteins. Various combinations of iap-1,iap-2, iap-3, and iap-4 are present in alphabaculoviruses, while betabaculoviruses carry iap-3, iap-5, and iap-6 [56]. In the EranNPV genome, three ORFs $(84,85$, and 107) were found to encode IAP homologs. According to the phylogenetic analysis (Figure 6) with selected baculoviral IAPs, IAP homologs in the EranNPV genome were separated into different groups. ORF84 that had a single BIR and RING belonged to IAP-2-like groups. Both ORF85 and 107 were made up of two copies of BIR and a RING, and they were clustered into IAP-2 and IAP-3 groups, respectively.

Tree scale: 1

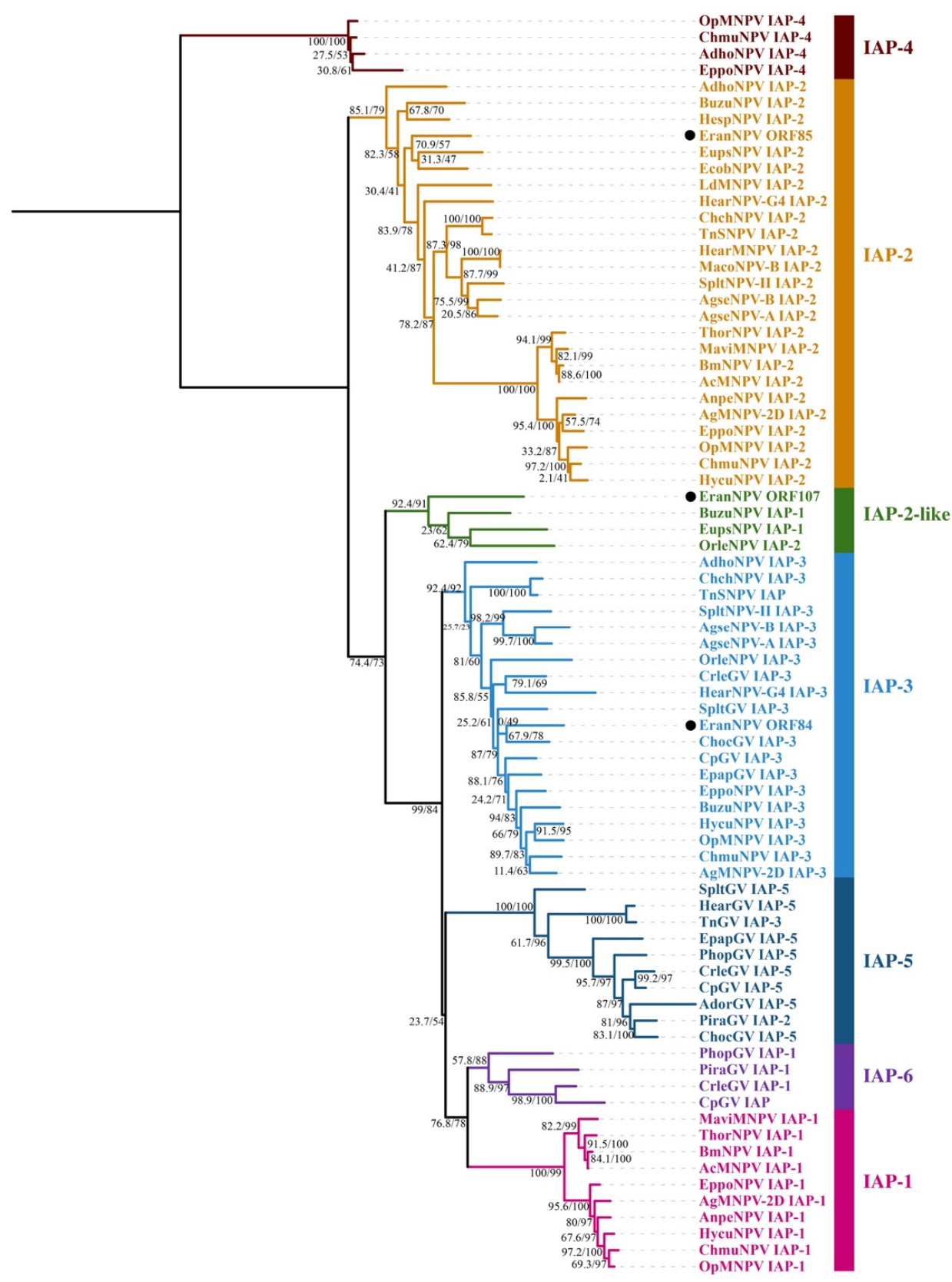

Figure 6. ML tree inferred from selected baculovirus IAP proteins using IQ-TREE. Bootstrap support values and SH-aLRT values are indicated on branches. IAP homologs in the EranNPV genome are marked by black dots. 
The $p 26$ gene is an alphabaculovirus-specific gene with a conserved position, and some alphabaculoviruses contain a second copy of this gene. The EranNPV encoded two copies of $p 26, p 26-1$, and $p 26-2$. Consistent with other group II alphabaculoviruses that have two copies of $p 26$, EranNPV p26-1 and p26-2 were adjacent to $p 10$ and iap-2, respectively.

The baculovirus $\mathrm{ChaB}$ proteins are present in all completely sequenced alphabaculoviruses except Urbanus proteus nucleopolyhedrovirus (UrprNPV) and some GVs, and most alphabaculoviruses contain two copies of ChaB. It has been demonstrated that the homologous gene of $C h a B$ encoded by HearNPV is transcribed in the early stage of infection and is involved in viral DNA replication and BV production [57]. The EranNPV was the fifth alphabaculovirus that contained three copies of ChaB. The other four viruses are BuzuNPV, Hemileuca sp. nucleopolyhedrovirus (HespNPV), Orgyia leucostigma nucleopolyhedrovirus (OrleNPV), and Artaxa digramma nucleopolyhedrovirus (ArdiNPV).

\subsection{The Potential of EranNPV as Bio-Pesticide}

In previously reported laboratory bioassays, the $\mathrm{LD}_{50}$ value of EranNPV against the third instar E. ankeraria larvae was $10^{6} \mathrm{OBs} /$ larva (regression equation: $\mathrm{y}=1.9621+$ 0.5056x; 95\% CI: $10^{5.86}-10^{6.16} \mathrm{OBs} /$ larva) and EranNPV was more virulent to early-instar larvae [58]. The average OB content of the second, third, fourth, and fifth instar E. ankeraria larvae and pupae dying from EranNPV infection were $6.96 \times 10^{7}, 2.76 \times 10^{8}, 5.34 \times 10^{8}$, $7.46 \times 10^{8} \mathrm{OBs} /$ larva, and $1.77 \times 10^{8} \mathrm{OBs} / \mathrm{pupa}$, respectively. The average OB content of the fifth instar E. ankeraria larvae can reach up to $1.5 \times 10^{9} \mathrm{OBs} /$ larva [58]. Compared with EranNPV kept in the refrigerator, EranNPV remaining on the trees for one year showed a certain activity with a decrease in toxicity of $63.2 \%$, indicating that the application of EranNPV in the forest has important implications for the prevalence of viral diseases in pest populations in the following year [58]. The LD $_{50}$ value of EranNPV against the third instar E. ankeraria larvae is higher than that of some other commercial baculoviruses against their host insects, such as HearNPV-C1 [59]. However, the performance of a baculovirus in the laboratory cannot completely reflect the control efficacy in the field.

As an attempt to explore the potential of EranNPV as a bio-pesticide to reduce the use of chemical pesticides, field trials in larch forests were conducted. The adjusted mortality of E. ankeraria larvae was $88.8 \%$ at the concentration of $1.09 \times 10^{8} \mathrm{OBs} / \mathrm{mL}$ on the twelfth day after spraying EranNPV, indicating that EranNPV was effective to control E. ankeraria under field conditions. However, only one concentration was used in this study; further field testing is required to determine the optimal dose of this virus for controlling E. ankeraria in the field. In a previous study, field trials of EranNPV against E. ankeraria larvae were also conducted in larch forests [60]. At a rate of $7.5 \times 10^{11} \mathrm{OBs} / \mathrm{ha}$, population decline rates were $65.9 \%$ and $90.3 \%$ at 15 and $23 \mathrm{~d}$ post applications, respectively. At a rate of $7.5 \times 10^{12} \mathrm{OBs} / \mathrm{ha}$, population decline rates were $68.4 \%$ and $97.8 \%$ at 15 and $23 \mathrm{~d}$ post applications, respectively. In the second year, four different dosages $\left(7.5 \times 10^{11}, 1.5 \times 10^{12}\right.$, $2.25 \times 10^{12}$, and $3 \times 10^{12} \mathrm{OBs} / \mathrm{ha}$ ) were used to perform field trials, and adjusted population decline rates were $72.4 \%, 68 \%, 77.5 \%$, and $91.0 \%$ at $18 \mathrm{~d}$ post applications, respectively. Additionally, the control efficacy of EranNPV at the dosage of $2.25 \times 10^{12} /$ ha was similar to that of fenvalerate at the concentration of $45 \mathrm{~mL} / \mathrm{ha}$. After applying the combination of EranNPV $\left(1.5 \times 10^{12} \mathrm{OBs} / \mathrm{ha}\right)$ and fenvalerate $(45 \mathrm{~mL} / \mathrm{ha})$, the population decline rate was $95.5 \%$ at $18 \mathrm{~d}$ post application [60]. Therefore, EranNPV has the potential to be developed as a microbial bio-pesticide for the management of E. ankeraria in the future.

\section{Conclusions}

In this work, EranNPV OBs were examined by electron microscopy, and the complete genome of this virus was sequenced and analyzed. EranNPV OBs exhibited irregular polyhedral shapes containing multiple enveloped rod-shaped virions, with a single nucleocapsid per virion. EranNPV was a novel group II alphabaculovirus and was most closely related to ApciNPV. In addition, field trials showed that EranNPV was effective in controlling E. ankeraria. These results provide a basis for the research on functional 
genomics of EranNPV as well as important data for genetic modification and developing this virus as bio-pesticide.

Supplementary Materials: The following are available online at https:/ / www.mdpi.com/article/10.3 390/v14010034/s1, Table S1: Basic information of 106 sequenced baculovirus genomes in GenBank, Table S2: 38 core genes of 106 genomes, Table S3: EranNPV genome annotation.

Author Contributions: Conceptualization, L.L. and D.W.; methodology, L.L. and Z.Z.; software, L.L.; validation, L.L. and D.W.; formal analysis, L.L.; investigation, L.L., Z.Z., C.L., L.Q. and D.W.; resources, Z.Z., L.Q. and D.W.; data curation, L.Q. and D.W.; writing-original draft preparation, L.L. and D.W.; writing-review and editing, L.L. and D.W.; visualization, L.L.; supervision, D.W.; project administration, D.W.; funding acquisition, D.W. All authors have read and agreed to the published version of the manuscript.

Funding: This research was funded by the National Natural Science Foundation of China (no. 31670659) and Shaanxi Key Project of Science and Technology (no. 2020zdzx03-03-02).

Institutional Review Board Statement: Not applicable.

Informed Consent Statement: Not applicable.

Data Availability Statement: No new data were created or analyzed in this study. Data sharing is not applicable to this article.

Conflicts of Interest: The authors declare no conflict of interest.

\section{References}

1. Szewczyk, B.; Hoyos-Carvajal, L.; Paluszek, M.; Skrzecz, W.; de Souza, M.L. Baculoviruses-re-emerging biopesticides. Biotechnol. Adv. 2006, 24, 143-160. [CrossRef]

2. Lacey, L.A.; Grzywacz, D.; Shapiro-Ilan, D.I.; Frutos, R.; Brownbridge, M.; Goettel, M.S. Insect pathogens as biological control agents: Back to the future. J. Invertebr. Pathol. 2015, 132, 1-41. [CrossRef]

3. Sun, X.L. History and current status of development and use of viral insecticides in China. Viruses 2015, 7, 306-319. [CrossRef] [PubMed]

4. Schaly, S.; Ghebretatios, M.; Prakash, S. Baculoviruses in gene therapy and personalized medicine. Biologics 2021, 15, 115-132 [CrossRef] [PubMed]

5. Possee, R.D.; Chambers, A.C.; Graves, L.P.; Aksular, M.; King, L.A. Recent developments in the use of baculovirus expression vectors. Curr. Issues Mol. Biol. 2019, 34, 215-230.

6. Rohrmann, G.F. Baculovirus Molecular Biology, 4th ed.; National Center for Biotechnology Information: Bethesda, MD, USA, 2019.

7. Blissard, G.W.; Theilmann, D.A. Baculovirus entry and egress from insect cells. Annu. Rev. Virol. 2018, 5, 113-139. [CrossRef] [PubMed]

8. Jehle, J.A.; Blissard, G.W.; Bonning, B.C.; Cory, J.S.; Herniou, E.A.; Rohrmann, G.F.; Theilmann, D.A.; Thiem, S.M.; Vlak, J.M. On the classification and nomenclature of baculoviruses: A proposal for revision. Arch. Virol. 2006, 151, 1257-1266. [CrossRef]

9. Harrison, R.L.; Herniou, E.A.; Jehle, J.A.; Theilmann, D.A.; Burand, J.P.; Becnel, J.J.; Krell, P.J.; van Oers, M.M.; Mowery, J.D.; Bauchan, G.R.; et al. ICTV virus taxonomy profile: Baculoviridae. J. Gen. Virol. 2018, 99, 1185-1186. [CrossRef]

10. Theze, J.; Lopez-Vaamonde, C.; Cory, J.S.; Herniou, E.A. Biodiversity, evolution and ecological specialization of baculoviruses: A treasure trove for future applied research. Viruses 2018, 10, 366. [CrossRef]

11. Ward, V.K.; Sneddon, K.M.B.; Hyink, O.; Kalmakoff, J. Baculovirus genomics: A resource for biocontrol. In Advances in Microbial Control of Insect Pests, 1st ed.; Upadhyay, R.K., Ed.; Springer: Boston, MA, USA, 2003; pp. 127-143.

12. Gencer, D.; Bayramoglu, Z.; Nalcacioglu, R.; Demirbag, Z.; Demir, I. Genome sequence analysis and organization of the Hyphantria cunea granulovirus (HycuGV-Hc1) from Turkey. Genomics 2020, 112, 459-466. [CrossRef]

13. Liu, F.; Li, F.; Zhang, S.; Kong, X.; Zhang, Z. Ultrastructure of antennal sensilla of Erannis ankeraria Staudinger (Lepidoptera: Geometridae). Microsc. Res. Tech. 2019, 82, 1903-1910. [CrossRef]

14. King, L.A.; Possee, R.D. Propagation of baculoviruses in insect larvae. In The Baculovirus Expression System: A Laboratory Guide, 1st ed.; Springer: Dordrecht, The Netherlands, 1992; pp. 180-194.

15. Li, X.F.; Yu, H.; Zhang, C.X.; Chen, H.; Wang, D. Helicoverpa armigera nucleopolyhedrovirus orf81 is a late gene involved in budded virus production. Arch. Virol. 2014, 159, 2011-2022. [CrossRef] [PubMed]

16. Benson, G. Tandem repeats finder: A program to analyze DNA sequences. Nucleic Acids Res. 1999, 27, 573-580. [CrossRef] [PubMed]

17. Altschul, S.F.; Madden, T.L.; Schaffer, A.A.; Zhang, J.H.; Zhang, Z.; Miller, W.; Lipman, D.J. Gapped BLAST and PSI-BLAST: A new generation of protein database search programs. Nucleic Acids Res. 1997, 25, 3389-3402. [CrossRef] 
18. Thompson, J.D.; Gibson, T.J.; Higgins, D.G. Multiple sequence alignment using ClustalW and ClustalX. Curr. Protoc. Bioinform. 2002, 1, 2.3.1-2.3.22. [CrossRef] [PubMed]

19. Lorenz, R.; Bernhart, S.H.; Höner Zu Siederdissen, C.; Tafer, H.; Flamm, C.; Stadler, P.F.; Hofacker, I.L. ViennaRNA Package 2.0. Algorithms Mol. Biol. 2011, 6, 26. [CrossRef]

20. Hu, Z.H.; Arif, B.M.; Jin, F.; Martens, J.W.M.; Chen, X.W.; Sun, J.S.; Zuidema, D.; Goldbach, R.W.; Vlak, J.M. Distinct gene arrangement in the Buzura suppressaria single-nucleocapsid nucleopolyhedrovirus genome. J. Gen. Virol. 1998, 79, 2841-2851. [CrossRef]

21. Katoh, K.; Standley, D.M. MAFFT multiple sequence alignment software version 7: Improvements in performance and usability Mol. Biol. Evol. 2013, 30, 772-780. [CrossRef]

22. Talavera, G.; Castresana, J. Improvement of phylogenies after removing divergent and ambiguously aligned blocks from protein sequence alignments. Syst. Biol. 2007, 56, 564-577. [CrossRef]

23. Zhang, D.; Gao, F.L.; Jakovlic, I.; Zou, H.; Zhang, J.; Li, W.X.; Wang, G.T. PhyloSuite: An integrated and scalable desktop platform for streamlined molecular sequence data management and evolutionary phylogenetics studies. Mol. Ecol. Resour. 2020, 20, 348-355. [CrossRef]

24. Lanfear, R.; Frandsen, P.B.; Wright, A.M.; Senfeld, T.; Calcott, B. PartitionFinder 2: New methods for selecting partitioned models of evolution for molecular and morphological phylogenetic analyses. Mol. Biol. Evol. 2017, 34, 772-773. [CrossRef] [PubMed]

25. Nguyen, L.T.; Schmidt, H.A.; von Haeseler, A.; Minh, B.Q. IQ-TREE: A fast and effective stochastic algorithm for estimating maximum-likelihood phylogenies. Mol. Biol. Evol. 2015, 32, 268-274. [CrossRef] [PubMed]

26. Minh, B.Q.; Nguyen, M.A.T.; von Haeseler, A. Ultrafast approximation for phylogenetic bootstrap. Mol. Biol. Evol. 2013, 30, 1188-1195. [CrossRef] [PubMed]

27. Guindon, S.; Dufayard, J.F.; Lefort, V.; Anisimova, M.; Hordijk, W.; Gascuel, O. New algorithms and methods to estimate maximum-likelihood phylogenies: Assessing the performance of PhyML 3.0. Syst. Biol. 2010, 59, 307-321. [CrossRef]

28. Kalyaanamoorthy, S.; Minh, B.Q.; Wong, T.K.F.; von Haeseler, A.; Jermiin, L.S. ModelFinder: Fast model selection for accurate phylogenetic estimates. Nat. Methods 2017, 14, 587-589.

29. Wennmann, J.T.; Keilwagen, J.; Jehle, J.A. Baculovirus Kimura two-parameter species demarcation criterion is confirmed by the distances of 38 core gene nucleotide sequences. J. Gen. Virol. 2018, 99, 1307-1320.

30. Harrison, R.L.; Mowery, J.D.; Bauchan, G.R.; Theilmann, D.A.; Erlandson, M.A. The complete genome sequence of a second alphabaculovirus from the true armyworm, Mythimna unipuncta: Implications for baculovirus phylogeny and host specificity. Virus Genes 2019, 55, 104-116. [CrossRef]

31. Marsberg, T.; Jukes, M.D.; Krejmer-Rabalska, M.; Rabalski, L.; Knox, C.M.; Moore, S.D.; Hill, M.P.; Szewczyk, B. Morphological, genetic and biological characterisation of a novel alphabaculovirus isolated from Cryptophlebia peltastica (Lepidoptera: Tortricidae) J. Invertebr. Pathol. 2018, 157, 90-99.

32. Harrison, R.L.; Rowley, D.L.; Mowery, J.D.; Bauchan, G.R.; Burand, J.P. The Operophtera brumata nucleopolyhedrovirus (OpbuNPV) represents an early, divergent lineage within genus Alphabaculovirus. Viruses 2017, 9, 307. [CrossRef]

33. Garavaglia, M.J.; Miele, S.A.B.; Iserte, J.A.; Belaich, M.N.; Ghiringhelli, P.D. The ac53, ac78, ac101, and ac103 genes are newly discovered core genes in the family Baculoviridae. J. Virol. 2012, 86, 12069-12079. [CrossRef]

34. Javed, M.A.; Biswas, S.; Willis, L.G.; Harris, S.; Pritchard, C.; van Oers, M.M.; Donly, B.C.; Erlandson, M.A.; Hegedus, D.D.; Theilmann, D.A. Autographa californica multiple nucleopolyhedrovirus AC83 is a per os infectivity factor (PIF) protein required for occlusion-derived virus (ODV) and budded virus nucleocapsid assembly as well as assembly of the PIF complex in ODV envelopes. J. Virol. 2017, 91, e02115-e02116. [CrossRef] [PubMed]

35. Van Oers, M.M.; Vlak, J.M. Baculovirus genomics. Curr. Drug Targets 2007, 8, 1051-1068. [CrossRef]

36. Nguyen, T.T.; Suryamohan, K.; Kuriakose, B.; Janakiraman, V.; Reichelt, M.; Chaudhuri, S.; Guillory, J.; Divakaran, N.; Rabins, P.; Goel, R. Comprehensive analysis of single molecule sequencing-derived complete genome and whole transcriptome of Hyposidra talaca nuclear polyhedrosis virus. Sci. Rep. 2018, 8, 8924. [CrossRef]

37. Guarino, L.A.; Gonzalez, M.A.; Summers, M.D. Complete sequence and enhancer function of the homologous DNA regions of Autographa californica nuclear polyhedrosis virus. J. Virol. 1986, 60, 224-229. [CrossRef] [PubMed]

38. Kool, M.; Voeten, J.T.; Goldbach, R.W.; Tramper, J.; Vlak, J.M. Identification of seven putative origins of Autographa californica multiple nucleocapsid nuclear polyhedrosis virus DNA replication. J. Gen. Virol. 1993, 74, 2661-2668. [CrossRef]

39. Hilton, S.; Winstanley, D. The origins of replication of granuloviruses. Arch. Virol. 2008, 153, 1527-1535. [CrossRef] [PubMed]

40. Jehle, J.A.; Lange, M.; Wang, H.L.; Hu, Z.H.; Wang, Y.J.; Hauschild, W. Molecular identification and phylogenetic analysis of baculoviruses from Lepidoptera. Virology 2006, 346, 180-193. [CrossRef] [PubMed]

41. Thumbi, D.K.; Béliveau, C.; Cusson, M.; Lapointe, R.; Lucarotti, C.J. Comparative genome sequence analysis of Choristoneura occidentalis Freeman and C. rosaceana Harris (Lepidoptera: Tortricidae) alphabaculoviruses. PLoS ONE 2013, 8, e68968. [CrossRef]

42. Pearson, M.N.; Rohrmann, G.F. Characterization of a baculovirus-encoded ATP-dependent DNA ligase. J. Virol. 1998, 72, 9142-9149. [CrossRef] [PubMed]

43. Ferrelli, M.L.; Pidre, M.L.; Ghiringhelli, P.D.; Torres, S.; Fabre, M.L.; Masson, T.; Cedola, M.T.; Sciocco-Cap, A.; Romanowski, V. Genomic analysis of an Argentinean isolate of Spodoptera frugiperda granulovirus reveals that various baculoviruses code for Lef-7 proteins with three F-box domains. PLOS ONE 2018, 13, e0202598. 
44. Mitchell, J.K.; Byers, N.M.; Friesen, P.D. Baculovirus F-box protein LEF-7 modifies the host DNA damage response to enhance virus multiplication. J. Virol. 2013, 87, 12592-12599. [CrossRef]

45. Yin, F.; Zhu, Z.; Liu, X.; Hou, D.; Wang, J.; Zhang, L.; Wang, M.; Kou, Z.; Wang, H.; Deng, F. The complete genome of a new betabaculovirus from Clostera anastomosis. PLoS ONE 2015, 10, e0132792. [CrossRef]

46. Wang, X.; Shang, Y.; Chen, C.; Liu, S.; Chang, M.; Zhang, N.; Hu, H.; Zhang, F.; Zhang, T.; Wang, Z.; et al. Baculovirus per os infectivity factor complex: Components and assembly. J. Virol. 2019, 93, e02053-e02118. [CrossRef]

47. Wang, R.R.; Deng, F.; Hou, D.H.; Zhao, Y.; Guo, L.; Wang, H.L.; Hu, Z.H. Proteomics of the Autographa californica nucleopolyhedrovirus budded virions. J. Virol. 2010, 84, 7233-7242. [CrossRef] [PubMed]

48. Hou, D.H.; Zhang, L.K.; Deng, F.; Fang, W.; Wang, R.R.; Liu, X.J.; Guo, L.; Rayner, S.; Chen, X.W.; Wang, H.L.; et al. Comparative proteomics reveal fundamental structural and functional differences between the two progeny phenotypes of a baculovirus. $J$. Virol. 2013, 87, 829-839. [CrossRef]

49. Hou, D.; Kuang, W.; Luo, S.; Zhang, F.; Zhou, F.; Chen, T.; Zhang, Y.; Wang, H.; Hu, Z.; Deng, F.; et al. Baculovirus ODV-E66 degrades larval peritrophic membrane to facilitate baculovirus oral infection. Virology 2019, 537, 157-164. [CrossRef] [PubMed]

50. Ferrelli, M.L.; Sciocco-Cap, A.; Berretta, M.F.; Belaich, M.N.; Ghiringhelli, P.D.; Romanowski, V. The baculoviral genome. In Viral Genomes-Molecular Structure, Diversity, Gene Expression Mechanisms and Host-Virus Interactions, 1st ed.; Garcia, M.L., Romanowski, V., Eds.; IntechOpen: London, UK, 2012; pp. 3-32.

51. Shu, R.H.; Meng, Q.; Miao, L.; Liang, H.B.; Chen, J.; Xu, Y.; Cheng, L.Q.; Jin, W.Y.; Qin, Q.L.; Zhang, H. Genome analysis of a novel clade $b$ betabaculovirus isolated from the legume pest Matsumuraeses phaseoli (Lepidoptera: Tortricidae). Viruses 2020, 12, 1068. [CrossRef] [PubMed]

52. Kang, W.K.; Imai, N.; Suzuki, M.; Iwanaga, M.; Matsumoto, S.; Zemskov, E.A. Interaction of Bombyx mori nucleopolyhedrovirus BRO-A and host cell protein laminin. Arch. Virol. 2003, 148, 99-113. [CrossRef]

53. Mikhallov, V.S.; Vanarsdall, A.L.; Rohrynann, G.F. Isolation and characterization of the DNA-binding protein (DBP) of the Autographa californica multiple nucleopolyhedrovirus. Virology 2008, 370, 415-429. [CrossRef]

54. Crook, N.E.; Clem, R.J.; Miller, L.K. An apoptosis-inhibiting baculovirus gene with a zinc finger-like motif. J. Virol. 1993, 67, 2168-2174. [CrossRef] [PubMed]

55. Birnbaum, M.J.; Clem, R.J.; Miller, L.K. An apoptosis-inhibiting gene from a nuclear polyhedrosis virus encoding a polypeptide with Cys/His sequence motifs. J. Virol. 1994, 68, 2521-2528. [CrossRef] [PubMed]

56. Clem, R.J. Viral IAPs, then and now. Semin. Cell Dev. Biol. 2015, 39, 72-79. [CrossRef]

57. Zheng, F.L.; Huang, Y.; Long, G.; Sun, X.L.; Wang, H.Z. Helicoverpa armigera single nucleocapsid nucleopolyhedrovirus ORF51 is a ChaB homologous gene involved in budded virus production and DNA replication. Virus Res. 2011, 155, 203-212. [CrossRef] [PubMed]

58. Sun, S.; Lü, Z.; Dai, R. A bioassay on toxicity of Erannis ankeraria Staudinger nuclear polyhedrosis virus. Acta Agric. Boreali Sin. 1988, 3, 64-70.

59. Guo, Z.J.; Ge, J.Q.; Wang, D.; Shao, Y.M.; Tang, Q.Y.; Zhang, C.X. Biological comparison of two genotypes of Helicoverpa armigera single-nucleocapsid nucleopolyhedrovirus. BioControl 2006, 51, 809-820. [CrossRef]

60. Sun, S.; Lü, Z.; Huang, G.; Dai, R.; Gao, Y.; Li, Z. The use of larch looper NPV to control larch looper Erannis ankeraria (Lepidoptera: Geometridae). Chin. J. Biol. Control 1990, 1, 46. 